In the past, interest has been focused on viruses which kill cells, such as poliovirus or smallpox virus. They are easier to study in the laboratory, and the pathogenesis of the diseases they cause is more obvious. It is now clear, however, that infection of cells by viruses without their death is commoner than had been supposed, and in the context of oncogenesis it is of paramount importance. It seems that RNA tumour viruses achieve this by budding from the cell surface without disrupting it. DNA tumour viruses, of which polyoma has been the most studied, ${ }^{1}$ may in fact follow a cell-killing course, but alternatively they may transform the cell to malignancy without killing it. The effect is obtained by partial replication of the viral genetic material, which then becomes incorporated in the cell in such a way that it multiplies as the cell divides. Such a fragment of the viral nucleic acid is small and could code at most for a few (perhaps two to four) proteins. It is presumably these proteins which directly or indirectly mediate the transformation to malignancy, and hence may hold the key to this process. The possibilities for study are immense. Apparently the tumour virus nucleic acid sometimes does not multiply, and the cells are altered only temporarily or for a few generations. This is known as abortive transformation. ${ }^{2}$

It would be surprising if man does not, like his domestic vertebrates, have at least some virus-induced tumours.
Nevertheless, at present the human wart (common or anogenital) is the only human neoplasm with a well-characterized virus as a well-proved cause. Admittedly there are some near misses. Various human adenoviruses cause malignant tumours in rodents; the virus of progressive multifocal leucoencephalopathy is found in highly compromising circumstances in the reticuloses; and the EB virus, which almost certainly causes infectious mononucleosis, is at least "associated" with the Burkitt lymphoma. Besides this, most of the types of human leukaemia and reticulosis are simulated by counterparts of viral origin in other species. Too much stress should not be laid on these instances, or at least not more than they can bear, but nevertheless it seems likely that sooner or later more human viruses causing genuine tumours will be discovered. Among other considerations, it is clear that the impossibility of working experimentally with human fetuses limits discovery in this field.

How much relevance does all this have to the patient? Perhaps the answer is in what Dr. Stoker himself wrote some years ago: "Admittedly the most spectacular advances have concerned molecules rather than patients, but it is the molecules which cause the diseases ...."3

Macpherson, I., British Medical Bulletin, 1967, 23, 144.

Stoker, M., Nature, 1968, 218, 234.

S Stoker, M., British Medical Bulletin, 1967, 23, 105

\section{Benign Intracranial Hypertension}

The causes of benign intracranial hypertension, or pseudotumour cerebri, are various and often undetermined. The main causes in the past were thought to be otitis media and other infections, as suggested by the older name otitic hydrocephalus. ${ }^{12}$ The unsuitability of the word hydrocephalus for a condition in which the ventricles are radiologically of normal size or even small was pointed out by J. Foley. ${ }^{3}$ He suggested the term benign intracranial hypertension for non-otitic cases.

The diagnosis must generally be by exclusion of other diseases. In children particularly, the distinction from a tumour in the posterior fossa is of paramount importance. Focal neurological signs (other than a sixth nerve palsy), fits, and mental deterioration should be absent, and investigations should exclude a mass lesion, intracranial infection, or obstructed ventricular system. Skull radiographs may show separation of the suiures and other signs of raised intracranial pressure. Contrast radiography is then needed, the choice lying between carotid or retrograde brachial arteriography and ventriculography. These methods can exclude a shift of the cranial contents due to a supratentorial mass and ventricular dilatation due to an infratentorial tumour. Pneumoencephalography is not advisable as the first investigation but may be helpful after a normal arteriogram has been obtained. Most patients recover without treatment. But, in a few, persistent intracranial hypertension threatens vision and requires treatment with repeated lumbar puncture or, if this fails, subtemporal decompression.

Benign intracranial hypertension has also been recognized in association with obesity ${ }^{4}$ and the menarche, ${ }^{5}$ excess and deficiency of vitamin $A,,^{6-8}$ hypoparathyroidism, ${ }^{9}$ acute iron deficiency anaemia, ${ }^{1011}$ treatment with tetracycline ${ }^{12}$ and nalidixic acid, ${ }^{13}$ and withdrawal of corticosteroid therapy. ${ }^{14}$
The last may give rise to difficult diagnostic and therapeutic problems. In this issue of the B.M.Y. Drs. B. G. R. Neville and J. Wilson report a series of seven children from the Hospital for Sick Children, Great Ormond Street, who were treated with corticosteroids or corticotrophin (A.C.T.H.) for various diseases and who developed benign intracranial hypertension when the dosage was reduced. The duration of treatment was at least four weeks except in two cases, and the rate of reduction was rather rapid in most cases. Two patients were being treated for neurological conditions in which cerebral oedema might have occurred independently. In only one case were special neuroradiological studies considered necessary. Neville and Wilson found that reintroduction of corticosteroids was effective treatment, in contrast to the earlier experience of $\mathrm{M}$. Greer. ${ }^{14}$ Among their suggestions on prevention and management the most important is that, after prolonged treatment with corticosteroids, withdrawal should be gradual over at least one month, and sudden reduction of the dose by half or more should be avoided. Special caution is

1 Symonds, C. P., Brain, 1937, 60, 531.

Symonds, Sir C., Neurology, 1956, 6, 681.

3 Foley, J., Brain, 1955, 78, 1.

4 Greer, M., Neurology (Minneapolis), 1965, 15, 382.

5 Greer, M., Neurology (Minneapolis), 1965, 15, 382.

- Greer, M., Neurology (Minneapolis), 1964, 14, 569.

- Gerber, A., Raab, A. P., and Sobel, A. E., American fournal of Medicine, Gerber, A., Raab, A. P., and Sobel, A. E., American fournal of Medicine,
1954, 16, 729.
Marie, J., and Sée, G., American fournal of Diseases of Children, 1954,

87,731 .

- Schwaber, J. R., and Blumberg, A. G., Annals of Internal Medicine, 1961 55, 1004 .

10 Sugar, O., Archives of Neurology and Psychiatry, 1953, 70, 86.

11 Ikkala, E., and Laitinen, L., Acta Haematologica, 1963, 29, 368.

12 Fields, J. P., Fournal of Pediatrics, 1961, 58, 74.

13 Boreus, L. O., and Sundström, B., British Medical fournal, 1967, 2, 744

14 Greer, M., Neurology (Minneapolis), 1963, 13, 439.

15 Huttenlocher, P. R., Hillman, R. E., and Hsia, Y. E., Fournal of Pediatrics $1970,76,902$. 
needed in conditions which may be associated with cerebral oedema.

Another paediatric condition in which raised intracranial pressure has recently been recognized is galactosaemia. P. R. Huttenlocher and his colleagues ${ }^{15}$ at Yale reported three newborn infants with galactosaemia who presented with a bulging fontanelle and jaundice. Meningitis was suspected in one case and sepsis in another until the true diagnosis was recognized. The optic discs are mentioned in only one case and are reported to have been normal. Rapid clinical improvement on a galactose-free diet was accompanied by return of the fontanelle tension to normal. The authors suggest that cerebral oedema in galactosaemia may be related to accumulation in the brain of dulcitol, the sugar alcohol derived from galactose, since animal experiments have shown this to accumulate in the lens of the eye in certain conditions.

The pathogenesis of raised intracranial pressure in the various clinical conditions mentioned is obscure in many cases and must clearly vary. Cases related to infections are less frequent than before, and more diverse causes are being recognized, among them medical treatment. Reports of further causes of it seem likely to come.

\section{World Medical Assembly}

The World Medical Association recently held its twentyfourth Assembly in Oslo, with the Norwegian Medical Association as host. Among the delegates from 27 national member associations were those from the United Kingdom and the Irish Republic, from Australia, Canada, Ghana, India, and Pakistan within the Commonwealth, and from South Africa. A report of the meeting appears at page 581 of this week's B.M.F.

It is no disparagement of the W.M.A.'s indefatigable secretariat, still less of the wonderfully hospitable host association, to say that the yield from the six days' discussion and debate was disappointingly small. There was a good exchange of information on malpractice claims and the ways these are dealt with in different parts of the world. A two-day debate on the general practitioner's future produced a useful session on his education: it should begin well before the student's entry to the wards, where first acquaintance with the intellectual allurements of hospital practice are apt to blind him to alternatives. And, lastly, after some hesitation the Assembly committed itself to a first statement on therapeutic abortion. Admittedly not perfect, perhaps, the statement seeks to safeguard the rights of the doctor within society as well as those of his patients, and so is welcome. There was also the customary conference of editors.

Naturally much else goes on at a large international congress than ever appears in its recorded proceedings. People meet their opposite numbers, delegations exchange views privately and discuss their difficulties, and so on. These things alone could be held to justify the W.M.A.'s Assemblies. Nevertheless these meetings are costly, and member associations look to them to be as productive as possible. The W.M.A. is dedicated to raising standards of medical education, ethics, and practice and to improving health care throughout the world. Its potential for advancing these high aims is real. It would therefore be unfortunate if a reputation for inconclusive debating were to lead to less support of its work.

Much of the trouble at Oslo was procedural. For instance, a cumbersome reference committee system impeded discussion. Too often debates were diffuse, too late, or even occasionally duplicated. The sheer weight of documentation tended to cloud the important issues, and when agreement was reached delegates were sometimes left wondering what would follow them. These are matters to which it may be hoped the W.M.A.'s council will turn its attention. The Assembly is the focal point of the year's activities. Inevitably, too, it catches the public eye. For both these reasons its streamlining is urgent.

\section{Overcrowded Broadmoor}

Founded in 1863 as a Criminal Lunatic Asylum, Broadmoor is an institution for the treatment under conditions of special security of patients of dangerous, violent, or criminal propensities to which intellectual subnormality as such does not contribute. It has undergone various changes in the hundred years of its history. For example, it has adopted the name of Broadmoor Hospital, added to its complement of inmates, and added a few feet to the height of its outer walls. Last week the Health Department announced that another institution of the same kind is to be put up in west Lancashire. Intended to accommodate 410 male patients, it will help to relieve "gross overcrowding" at Broadmoor.

The Mental Health Act 1959 transferred the emphasis for the care of mentally abnormal offenders from the prison service to the mental hospitals and so increased the demand for admissions to Broadmoor. But because of its limited accommodation only the very worst of such patients could be crammed in, thus leaving the rest to be managed in conventional mental hospitals, all ill-equipped for the task. The pressure is further heightened as a result of Section 72 of the Act, which replaced previous equivalent legislation. Under this section prisoners deemed to be suffering from mental disorder during their sentence can be transferred from prison to a mental hospital, which in the case of the highly dangerous can only mean to Broadmoor. P. McGrath, ${ }^{1}$ its physician superintendent, has reported that in $196522 \%$ of 157 admissions were so admitted. A more recent example of the use of Section 72 is seen in the return to Broadmoor of Martin Victor Frape, ${ }^{2}$ one of the Parkhurst Prison rioters, after their much-publicized trial.

The very nature of the work at Broadmoor and the pressures to which it is subjected, both internal and external, make it, despite its sylvan setting, a difficult institution to staff adequately. Yet it has an incomparable tradition of service to itself and to the community at large. Its record of escapes is by no means the most important criterion, yet since 1880 the list is limited to only 17 people. One was a child murderer who within hours of his cunningly planned escape killed another small girl. His deed serves as a constant reminder that in this hospital security must come first.

It is in the context of security that the present rumblings of

1 McGrath, P. G., Proceedings of the Royal Society of Medicine, 1966, 59, 699. Guardian, 4 August, 1970, p. 5.

Report of the Committee on Senior Nursing Staff Structure. London H.M.S.O., 1966.

- House of Commons, 2nd Report from the Estimates Committee, The Specia Hospitals and the State Hospital. London, H.M.S.O., 1968.

- British Medical fournal, 1968, 1, 783. 